\title{
EVALUATION OF A THREE-DIMENSIONAL MEASUREMENT FOR DIFFERENTIATION BETWEEN THE SKELETAL CLASSES
}

\author{
Amr El-Beialy*, Mohammed Ghoneim **, Khaled Aboul Rous**, \\ Amr Abo El-Ezz ${ }^{* *}$, Essam Nassef Selim ${ }^{* * *}$ and Yehya Mostafa****
}

\begin{abstract}
Despite the fact that 3D volume is versatile, the current 3D analyses are still saturated with a $2 \mathrm{D}$ spirit. We aim at presenting a new three-dimensional measurement for skeletal classification. A sample of 30 subjects having normal occlusion and balanced facial proportions and 30 patients with skeletal component of malocclusion were scanned using CBCT. A new measurement was tested to determine the skeletal classification. Results showed that the new measurements proved sensitive in delineating the different skeletal classes
\end{abstract}

\section{INTRODUCTION}

Despite the fact that the $3 \mathrm{D}$ volume is versatile, the current 3D analyses are based upon 2D background and landmarks. ${ }^{1}$ In order to come up with a comprehensive 3D analysis, genuine 3D landmarks and 3D measurements should be evaluated separately without the influence of the two-dimensional experience. ${ }^{1,2}$

After years of using ANB angle in determining the skeletal classification, they proved to be influenced by other factors such as increased facial height, vertical and anteroposterior position of Nasion point, and are hence questionable in categorization of skeletal discrepancies in border line cases. ${ }^{3}$
The purpose of this study is to investigate a new 3D measurement for differentiation between the different skeletal classes. Measurements include ratio A-Facial plane (Or)/B-Facial plane (Or).

\section{MATERIALS AND METHODS}

A sample of 60 subjects were scanned using a low dose Cone beam Computed Tomography (CBCT) scanner.* The scanner has a limited field of view of the CBCT scanner used in this study (6-inch $=15$ $\mathrm{cm})$. The sample comprised 30 subjects having normal occlusion and balanced facial profiles, and 30 subjects with clinically evident skeletal class 2 and class 3 malocclusion. Dropouts were due

\footnotetext{
* Lecturer Department of Orthodontics, Faculty of Dentistry, Cairo university

** BDS, MSc (Cairo University)

*** Professor Department of Orthodontics, Faculty of Dentistry, Cairo University
} 
to subjects with large anteroposterior dentofacial depth that exceeded the focal trough of the CBCT scanner. Besides, the difficulty of identifying some marginal landmarks lead to the exclusion of cases, to leave out 14 cases having balanced facial profiles and 18 patients with skeletal discrepancy (skeletal class 2 and Class 3).

In order for the CBCT to compute all our diagnostic information from cast analysis to detofacial analysis, the subjects wore a mandibular radiolucent splint during CBCT imaging. This inter-maxillary separation offers $2 \mathrm{~mm}$ of anterior separation between both arches in all the skeletal classes. This procedure guarantees reproducibility, undisrupted facial form, centric condylar position concurrently with feasibility for occlusal analysis, separation of the maxillary and mandibular teeth and hence digital simulation of the orthodontic and orthognathic treatment. ${ }^{4}$

In the current study, the point of origin for the coordinate system was set the point $\mathrm{N}$. The reference planes used for orientation and measurement were the Frankfurt Horizontal plane constructed of bilateral Orbitale points and the right Porion. The midsagittal plane is perpendicular to the $\mathrm{FH}$ at point $\mathrm{N}$, and the Facial plane was set perpendicular to the midsagittal plane at point Orbitale (Fig 1).

Categorization of the patients into the skeletal classes was done by measuring the ANB angle (golden standard) used in 2D analyses. Then the new proposed ratio was accomplished by measuring the distance from points A and B (Fig.2) to the Facial plane at point Orbitale (Or) (Fig 3). The ratio between the distance from point $A$ to the facial plane at Orbitele point/ the distance from point B to the facial plane at Orbitale point [A-Facial plane (Or)/B-Facial plane (Or)] was calculated for each subject in the three classes.

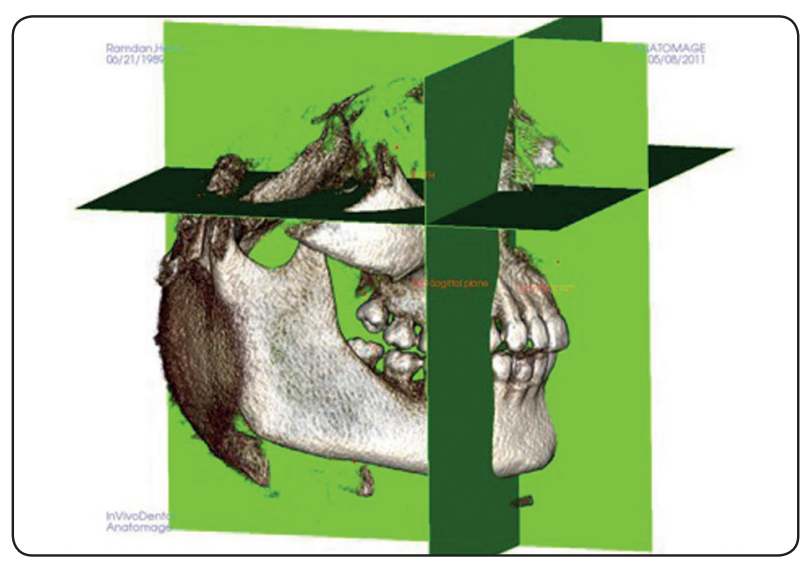

Fig. (1) Showing Midsagittal plane and Frontal Plane at or

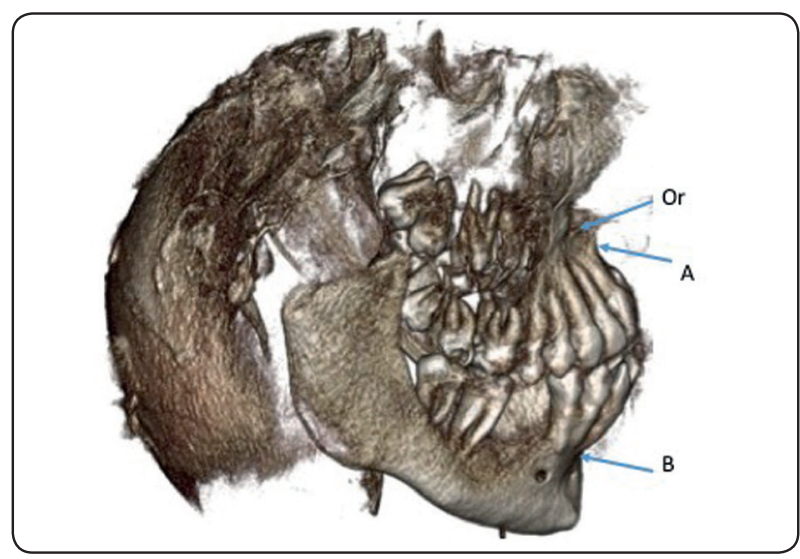

Fig. (2) Showing point A, Band Orbitale

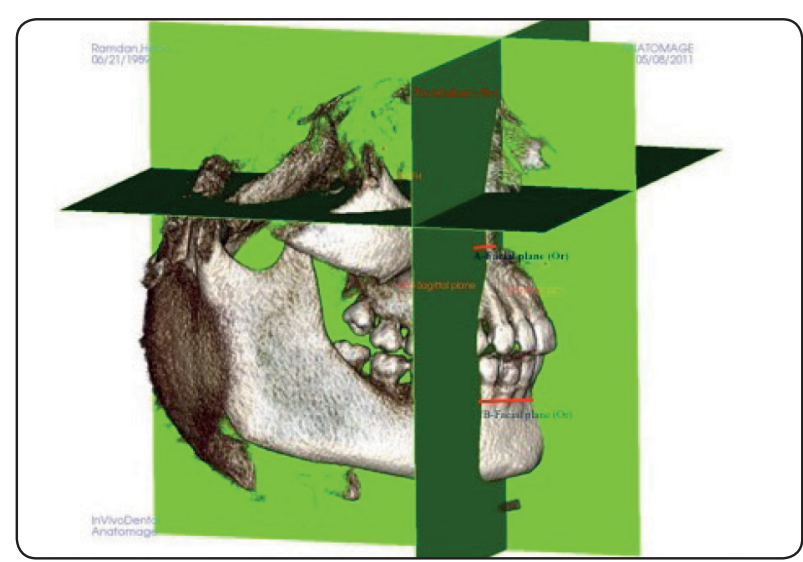

Fig. (3) A-Facial plane (Or) and B-Facial plane (Or)

* Galileos Sirona Dental Systems Inc., Bensheim, Germany 
Statistical tests for sensitivity and specificity based upon the true positive, false positive, true negative and false negative values were used.

\section{RESULTS}

The statistical test revealed the high sensitivity and specificity of the new ratio of the distance from point A to the Frontal plane at Orbitale point/ point $\mathrm{B}$ to the Frontal plane at Orbitale point in differentiating between the three skeletal classes. However, the sensitivity and specificity and diagnostic accuracy were better in delineation of the skeletal class 2 cases (Table 1) than skeletal class 3 cases (Table 2).

TABLE (1) Diagnostic accuracy for discrimination of skeletal class 2 Subjects

\begin{tabular}{|c|c|c|c|c|}
\hline & & \multicolumn{2}{|c|}{$\begin{array}{c}\text { Patients with skeletal class } 2 \\
\text { as confirmed by ANB }\end{array}$} & \\
\hline & & $\begin{array}{l}\text { Condition positive } \\
\text { (skeletal class } 2 \text { ) }\end{array}$ & $\begin{array}{l}\text { Condition Negative } \\
\text { (skeletal class } 1 \text { ) }\end{array}$ & \\
\hline \multirow{2}{*}{$\begin{array}{l}\text { A- Facial plane (or) / } \\
\text { B- Facial plane (or) / }\end{array}$} & Test outcome positive & $\begin{array}{l}\text { True positive } \\
=10\end{array}$ & $\begin{array}{l}\text { False positive } \\
\quad=1\end{array}$ & $\begin{array}{l}\text { Positive predictive value } \\
\qquad \begin{array}{c}=10 / 11 \\
=90.9 \%\end{array}\end{array}$ \\
\hline & $\begin{array}{c}\text { Test outcome } \\
\text { Negative }\end{array}$ & $\begin{array}{c}\text { False Negative } \\
\quad=1\end{array}$ & $\begin{array}{c}\text { True Negative } \\
=13\end{array}$ & $\begin{array}{l}\text { Negative predictive value } \\
\qquad \begin{array}{c}=13 / 14 \\
=92.9 \%\end{array}\end{array}$ \\
\hline \multicolumn{2}{|c|}{$\begin{array}{l}\text { Diagnostic Accuracy } \\
\quad=23 / 25=92 \%\end{array}$} & $\begin{array}{l}\text { Sensitivity } \\
\quad=10 / 11 \\
=90.9 \%\end{array}$ & $\begin{array}{l}\text { Sensitivity } \\
=13 / 14 \\
=92.9 \%\end{array}$ & \\
\hline
\end{tabular}

TABLE (2) Diagnostic accuracy for discrimination of skeletal class 3 Subjects

\begin{tabular}{|c|c|c|c|c|}
\hline & & \multicolumn{2}{|c|}{$\begin{array}{c}\text { Patients with skeletal class } 3 \\
\text { as confirmed by ANB }\end{array}$} & \\
\hline & & $\begin{array}{l}\text { Condition positive } \\
\text { (skeletal class } 3 \text { ) }\end{array}$ & $\begin{array}{c}\text { Condition Negative } \\
\text { (skeletal class } 1 \text { ) }\end{array}$ & \\
\hline \multirow{2}{*}{$\begin{array}{l}\text { A- Facial plane (or) / } \\
\text { B- Facial plane (or) / }\end{array}$} & $\begin{array}{l}\text { Test outcome } \\
\text { positive }\end{array}$ & $\begin{array}{l}\text { True positive } \\
\quad=5\end{array}$ & $\begin{array}{l}\text { False positive } \\
\quad=2\end{array}$ & $\begin{array}{c}\text { Positive predictive value } \\
\begin{array}{c}=5 / 7 \\
=71.4 \%\end{array}\end{array}$ \\
\hline & $\begin{array}{l}\text { Test outcome } \\
\text { Negative }\end{array}$ & $\begin{array}{c}\text { False Negative } \\
=1\end{array}$ & $\begin{array}{l}\text { True Negative } \\
=13\end{array}$ & $\begin{array}{c}\text { Negative predictive value } \\
\qquad \begin{array}{c}=13 / 14 \\
=92.9 \%\end{array}\end{array}$ \\
\hline \multicolumn{2}{|c|}{$\begin{array}{l}\text { Diagnostic Accuracy } \\
\quad=18 / 21=85.7 \%\end{array}$} & $\begin{array}{l}\text { Sensitivity } \\
\quad=5 / 6 \\
=83.3 \%\end{array}$ & $\begin{array}{l}\text { Sensitivity } \\
\quad=13 / 15 \\
=86.7 \%\end{array}$ & \\
\hline
\end{tabular}




\section{DISCUSSION}

The three-dimensional visualization of the dentofacial structures has become more versatile. ${ }^{5}$ The three-dimensional rendering of the cone beam computed tomographic cuts offers capabilities of identification of new landmarks that could not be visualized using another imaging modality. ${ }^{1}$

The capability of a visualizing the orthogonal sections for proper localization of landmarks on the three-dimensional volume has added much to the accuracy and reproducibility of the threedimensional analysis. ${ }^{6}$ The accuracy of localization of landmarks is the corner stone for formulation of three-dimensional analyses.

On the other hand, the capabilities offered by the current three-dimensional CBCT opens the door for formulation and testing of new analyses. In the current study, new formulas are being tested to differentiate between the different skeletal classes.

The limited field of view of the CBCT scanner used in this study $(6-i n c h=15 \mathrm{~cm})$ was responsible for some artifacts. The adult sample with an average skull size, made volumetric cone cut and truncated view artifacts common imaging hurdles. Not to mention the skeletal class 3 patients with large anteroposterior dentofacial depth. Besides the ALARA based Galileos machine produced low-resolution images. ${ }^{7,8,9}$ This was evident in the difficulty of identifying some marginal landmarks such as N, S, Po, and Me in certain cases. This lead to exclusion of cases to leave out 14 cases having balanced facial profiles and 18 patients with skeletal discrepancy (skeletal class 2 and Class 3).

The results showed the high sensitivity and specificity of the new ratio of the distance from point A to the Frontal plane at Orbitale point/point B to the Frontal plane at Orbitale point in delineating the three skeletal classes. This finding can be reverted back to the high accuracy in identification of cephalometric landmarks on 3D volumes, ${ }^{10,11}$ and can be considered an addition to the well-known measurements used for differentiation of the different skeletal classes such as the ANB angle and the Witts appraisal. However, based on the sensitivity and specificity tests, the new measurement was more sensitive in delineating skeletal class 2 subjects than skeletal class 3 subjects. Therefore, a new threedimensional measurement that is still based on 2D landmarks and spirit is ready to be tested before integration into three-dimensional analyses.

\section{CONCLUSION}

From the above mentioned results, we can conclude that the ratio between the distance A-Facial plane (Or)/B-Facial plane (Or) showed promising results as a new measurement used for skeletal classification. This opens the door for generation of a new craniofacial analysis, with testig should be done a larger sample size that is more representable of the population.

\section{REFERENCES}

1. Swennen GRJ, Schtyser F, Hausamen JE. Three-dimensional cephalometry A color atlas and manual. SpringerVerlag Berlin Heidelberg 2006.

2. Farman AG, Scarfe WC. The Basics of Maxillofacial Cone Beam Computed Tomography. Semin Orthod 2009; 15:2-13.

3. Taylor CM. Changes in the relationship of nasion, point $\mathrm{A}$, and point $\mathrm{B}$ and the effect upon ANB. Am J Orthod.1969;143-163.

4. El-Beialy AR, Mostafa YA. Inter-Occlusal Separation in CBCT Imaging:Rationale and Method. Open Journal of Medical Imaging, 2012,2,76-79.

5. Methods for managing 3-dimensional volumes Othman AA, El-Beialy AR, Fawzy SA, Kandil AH, El-Bialy AM, and Mostafa YA. Am J Orthod Dentofacial Orthop 2010;137:266-73.

6. Van Vlijmen OJC, Maal T, Berge' SJ, Bronkhorst EM, Katsaros C, Kuijpers-Jagtman AM. A comparison between 2D and 3D cephalometry on CBCT scans of human skulls. Int J Oral Maxillofac Surg 2010;39: 156-60. 
7. Farman AG. ALARA still applies. Oral Surg Oral Med Oral Pathol Oral Radiol Endod 2005;100:395-7.

8. Brooks SL. Radiation Doses of Common Dental Radiographic Examinations: A Review. Acta Stomatol Croat. 2008;42(3):207-17.

9. Brooks SL.CBCT dosimetry: Orthodontic Considerations. Semin Orthod 2009;15:14-8.
10. Lagravere M, Carey J, Toogood R, Major P. Three-dimensional accuracy of measurements made with software on cone-beam computed tomography images. Am J Orthod Dentofacial Orthop 2008;134:112-6.

11. Eggers G, Klein J, Welzel T, Muhling J. Geometric accuracy of digital volume tomography and conventional computed tomography. Br J Oral Maxillofac Surg 2008; 46:639-44. 